Diaz-Aznar, Trujillo-Torres, Garcia, \& Jimenez. Sociodemographic factors influencing smartphone addiction in university students.

\title{
Sociodemographic factors influencing smartphone addiction in university students
}

\author{
Inmaculada Aznar-Díaz * \\ University of Granada \\ Juan-Manuel Trujillo-Torres \\ University of Granada \\ Santiago Alonso-García \\ University of Granada \\ Carmen Rodríguez-Jiménez \\ University of Granada \\ *Corresponding Author: iaznar@ugr.es \\ Received : 03.07.2019 \\ Accepted : 08.09.2019
}

How to cite this paper: Diaz-Aznar, I., Trujillo-Torres, J. M., Garcia, S. A., \& Jimenez, C. R. (2019). Sociodemographic factors influencing smartphone addiction in university students. Research in Social Sciences and Technology, 4(2), 137-146.

\section{Abstract}

The development of mobile devices has affected the way of life of university students, affecting their daily habits and sometimes their health. Specifically, in recent years a series of illnesses have developed as a result of the constant use of smartphones by the university population, which has come to be catalogued as an at-risk population. The aim of this work was to analyze the sociodemographic factors that influence the smartphone addiction of university students. For the measurement of the levels of addiction, the standardized instrument Smartphone Addiction Scale was used in a sample of 385 students from the University of Granada, Spain. A multiple linear regression model was used as a statistical test, highlighting that the factor influencing smartphone addiction is the time of use. Finally, the study includes a series of implications derived from the results obtained, with the aim of establishing preventive measures to help to mitigate smartphone addiction.

Keywords: Mobile devices, Smartphone addiction, Internet addiction, Higher education

\section{Introduction}

Initially, the democratization of information and communication technologies (ICT) enabled their use at the social level (Tarman et. al, 2015; 2019). Today, business competitiveness in technology has made the prices of mobile devices affordable for the general public, boosting consumption and increasing the number of hours dedicated to these devices. Among them, the smartphone has reached great popularity due to its characteristics and reduced dimensions. 
Diaz-Aznar, Trujillo-Torres, Garcia, \& Jimenez. Sociodemographic factors influencing smartphone addiction in university students.

In Spain, consumption has reached such an extreme that, of populations that spend the most time on smartphones, Spain is fifth in the world (Rodríguez, 2017). This abusive use is mostly by teenagers (Ruiz-Palmero, Sánchez-Rodríguez, \& Trujillo-Torres, 2016) and young adults, who belong to the generation that has grown up with technology and is more prone to a certain addiction to the smartphone (Wang, Sigerson, \& Cheng, 2019).

This type of addiction has been closely linked to Internet addiction (Jeong, Suh, \& Gweon, 2019), forming part of the behavioral addictions. One of its variants is nomophobia, which is characterized by a state of anxiety caused by the impossibility of having access to a smartphone (Anshari, Alas, \& Sulaiman, 2019).

For its part, addiction to the smartphone has been increased by the growth and development of social networks and the need for the user to be connected as long as possible to them (Cha \& Seo, 2018; Noë, Turner, Linden, Allen, Winkens, \& Whitaker, 2019). At the same time, the development of videogames through mobile applications (apps) has led to a greater dedication to smartphones and, therefore, a greater predisposition to addiction (Gaspar \& Cuesta, 2015).

This problem associated with the abuse of the Internet entails other risky behavior on the Internet, such as being an aggressor or victim of cyberbullying (Qudah, Salamah, Attallah, Hashem, Alfnan, Aljomaa, \& Ateik, 2019). Thus, excessive use of mobile devices accentuates the possibilities of exercising or receiving aggressions online.

In addition, the largest population at risk of smartphone addiction are university students (Polo, Mendo, León, \& Castaño, 2017). Therefore, a priori, it is a well-educated population that is studying at a higher level and may develop negative consequences such as depression and anxiety (Boumosleh \& Jaalouk, 2017; Kim, Park, Kim, Pan, Lee, \& McIntyre, 2019), worsening physical health (Kumcagiz, 2019), and low academic performance (Alzubi, 2019; Chang, Chiu, Chen, Chiang, Miao, Chuang, \& Liu, 2019).

In spite of these consequences for the user, the educational field is beginning to introduce the mobile device to improve the teaching-learning process in the classroom. This methodology is called mobile learning (Hinojo, Aznar, \& Romero, 2018). In this line, it is essential that teachers implement measures for education in the good use of the smartphone and the application of good teaching practices (Aznar, Cáceres, \& Romero, 2018) in order to reduce malpractice with the mobile device.

Some previous studies that focus attention on smartphone addiction on the part of university students pick up positive aspects that can predict this type of behavior. Thus, self-control is a key piece in reducing smartphone addiction (Heo \& Lee, 2018). Age influences when presenting a predisposition to smartphone addiction in university students (Gligor \& Mozos, 2019). Time of use is directly related to smartphone addiction (Rozgonjuk, Elhai, Täht, Vassil, Levine, \& 
Diaz-Aznar, Trujillo-Torres, Garcia, \& Jimenez. Sociodemographic factors influencing smartphone addiction in university students.

Asmundson, 2019). The individual differences of university students explain the excessive use of technology (Elhai, Rozgonjuk, Yildirim, Alghraibeh, \& Alafnan, 2019). A high degree of awareness is linked to a low addiction to smartphones in university students (Lian, 2018). On the other hand, other studies warn that smartphone addiction correlates positively with anxiety (Konan, Durmus, Türkoglu, \& Bakir, 2018). Depression, anxiety, and smartphone addiction in college students showed a significant positive correlation (Kim \& Kwon, 2019), and high smartphone use and low social support is positively and significantly related to smartphone addiction (Herrero, Urueña, Torres, \& Hidalgo, 2019; Kuss, Harkin, Kanjo, \& Billieux, 2019).

Based on these considerations, the objectives of the study were to evaluate the degree of smartphone addiction of university students in the Primary Education degree at the University of Granada and to determine the sociodemographic factors that influence smartphone addiction. There were also established as research questions:

RQ1: What is the degree of addiction to the smartphone (understood as the abusive use of the internet that interferes with daily life) of future teachers?

RQ2: Are there differences between gender (male or female), age, educational level (level attained in the educational system), employment status, and time spent on smartphone addiction?

RQ3: Does gender, age, educational level, employment status, and time spent influence smartphone addiction?

\section{Method}

\section{Participants}

The sample under study was extracted from a population of students of the Faculty of Education Sciences at the University of Granada. An online survey based on a standardized questionnaire was applied to different grade levels in Primary Education. The selection of the sample was made on the basis of stratified random sampling, taking into consideration that the sample size reached a significant sample size at $95 \%$ confidence with a margin of error of $5 \%$ $(\mathrm{N}=385)$. The characteristics of the participants are shown in Table 1 . The sample consisted of a total of 147 men and 238 women ages 18-55 ( $M=23.98 ; S D=5.40)$. 
Diaz-Aznar, Trujillo-Torres, Garcia, \& Jimenez. Sociodemographic factors influencing smartphone addiction in university students.

Table 1.

Socio-demographic data

\begin{tabular}{lll}
\hline & $N$ & $M(S D)$ or \% \\
\hline Gender & 147 & 38.2 \\
Male & 238 & 61.8 \\
Female & 385 & \\
& 123 & $23.98(5.40)$ \\
Age & 134 & 31.9 \\
$18-21$ & 85 & 34.8 \\
$22-25$ & 43 & 22.1 \\
$26-29$ & & 11.2 \\
30 or more & & \\
& 358 & 93 \\
Studies & 27 & 7 \\
A-Levels & & \\
High-level Vocational Training & & \\
& 199 & 51.7 \\
Employment situation & 186 & 48.3 \\
Active & & \\
Inactive & & 30.6 \\
& 118 & 37.8 \\
Usage time (hours) & 146 & 17.7 \\
Less than 1 & 68 & 13.9 \\
Between 1-2 & 53 & \\
Between 2-3 & & \\
More than 3 & & \\
\hline
\end{tabular}

\section{Measures}

\section{Smartphone Addiction Scale (SAS-SV)}

Addiction to the smartphone was evaluated with the SAS application in its short version. This scale measures smartphone addiction through 10 items. The response mode is based on a Likert scale of four levels ranging from 1 (Strongly disagree) to 4 (Strongly agree). The scores obtained in each item are added up, being able to reach from a minimum of 10 points to a maximum of 40; the scores close to 40 indicate a greater degree of addiction to the smartphone. This scale has good psychometric properties and internal consistency (Kwon, Kim, Cho, \& Yang, 2013). Reliability in this study was great (Cronbach's a $=0.82$ ).

Data analysis

The data were analyzed using different statistical tests with the help of the IBM SPSS version 24 quantitative analysis software. From this, the statistical-descriptive (RQ1 and RQ2) values were calculated and the significance of the independent variables in smartphone addiction was verified from the establishment of a multiple linear regression model (RQ3). 
Diaz-Aznar, Trujillo-Torres, Garcia, \& Jimenez. Sociodemographic factors influencing smartphone addiction in university students.

\section{Results}

The descriptive statistical values, which answer RQ1 and RQ2, include scores that fall within the range of smartphone addiction in age (18-21, 22-25, and 30 years or older), educational level (superior grade), employment situation (inactive), and time of use (between 2-3 and more than 3 hours). At the same time, statistically significant differences are established between different groups (Table 2). Specifically, these are the age groups $18-21$ and $26-29$ years ( $p=$ $0.003), 22-25$ and $26-29$ years ( $p=0.007), 26-29$ and 30 years or more $(p=0.032)$; employment status $(p=0.011)$; and between all times of use.

\section{Table 2.}

Descriptive statistics and test $t$

\begin{tabular}{|c|c|c|c|c|c|}
\hline Independent variable & $M$ & $S D$ & $T$ & $\mathrm{df}$ & $p$ \\
\hline \multicolumn{6}{|l|}{ Gender } \\
\hline Male & 19.88 & 5.70 & -0.072 & 383 & 0.943 \\
\hline Female & 19.92 & 5.61 & & & \\
\hline \multicolumn{6}{|l|}{ Age } \\
\hline $18-21$ & 20.56 & 5.86 & & & \\
\hline $18-21 / 22-25$ & & & 0.521 & 255 & 0.603 \\
\hline $18-21 / 26-29$ & & & 3.091 & 206 & 0.003 \\
\hline $18-21 / 30$ or more & & & 0.112 & 164 & 0.911 \\
\hline $22-25$ & 20.19 & 5.43 & & & \\
\hline $22-25 / 26-29$ & & & 2.702 & 217 & 0.007 \\
\hline $22-25 / 30$ or more & & & -0.250 & 175 & 0.803 \\
\hline $26-29$ & 18.22 & 4.97 & -2.165 & 126 & 0.032 \\
\hline 30 or more & 20.44 & 6.35 & & & \\
\hline \multicolumn{6}{|l|}{ Studies } \\
\hline A-Levels & 19.89 & 5.66 & -0.162 & 383 & 0.871 \\
\hline High-level Vocational Training & 20.07 & 5.35 & & & \\
\hline \multicolumn{6}{|l|}{ Employment situation } \\
\hline Active & 19.20 & 5.76 & -2.566 & 383 & 0.011 \\
\hline Inactive & 20.66 & 5.41 & & & \\
\hline \multicolumn{6}{|l|}{ Usage time } \\
\hline Less than 1 & 17.58 & 4.66 & & & \\
\hline Less than 1/Between 1-2 & & & -2.949 & 262 & 0.003 \\
\hline Less than 1 / Between 2-3 & & & -5.285 & 184 & 0.000 \\
\hline Less than 1 / More than 3 & & & -8.008 & 169 & 0.000 \\
\hline Between 1-2 & 19.36 & 5.04 & & & \\
\hline Between 1-2/Between 2-3 & & & -2.950 & 212 & 0.004 \\
\hline Between 1-2/ More than 3 & & & -5.882 & 197 & 0.000 \\
\hline Between 2-3 & 21.62 & 5.59 & -2.603 & 119 & 0.010 \\
\hline More than 3 & 24.40 & 6.10 & & & \\
\hline
\end{tabular}

The multiple linear regression model, which answers RQ3, has a good fit and is significant (Fstatistic $=15.341 ; p=0.000$ ) (Table 3 ). It is established that the only significant variable in smartphone addiction is time of use $(p=0.000)$. The remaining variables are not significant to explain the addiction. 
Diaz-Aznar, Trujillo-Torres, Garcia, \& Jimenez. Sociodemographic factors influencing smartphone addiction in university students.

Table 3.

Multiple linear regression analysis

\begin{tabular}{llllllll}
\hline & Independent variable & $B$ & SE & $T$ & $p$ & $B$ & $R^{2}$ \\
\hline Smartphone & Gender & -.0184 & 0.569 & -0.324 & 0.746 & -0.016 & 0.16 \\
addiction & Age & 0.523 & 0.328 & 1.597 & 0.111 & 0.092 & \\
& Studies & -0.436 & 0.528 & -0.825 & 0.410 & -0.039 & \\
& Employment situation & 0.996 & 0.610 & 1.633 & 0.103 & 0.088 & \\
& Usage time & 2.321 & 0.281 & 8.263 & 0.000 & $0.415^{* * *}$ & \\
\hline
\end{tabular}

Note: $* p<0.05 ; * * p<0.01 ; * * * p<0.001$

\section{Discussion and Conclusions}

The data obtained confirm that university students are a population at risk for technological addiction (Polo et al., 2017). It is detected that there is a greater addiction in young adults and in adults aged 30 years or more, with statistically significant differences between age groups. However, the 26-29 age group is not addictive. On the other hand, there are significant differences in the work situation; the fact of being inactive is an incentive for smartphone addiction. Having more free time intervenes in the use of that time to devote it to the mobile device.

Differences between independent variables also indicate that the sociodemographic factors of university students may explain smartphone addiction (Elhai et al., 2019). On the other hand, longer usage time indicates a greater addiction to the smartphone, with significant differences being found between all estimated usage bands. This is confirmed in the multiple linear regression analysis where the time invested is the only variable that influences significantly. Thus, time of use is significantly related to smartphone addiction (Rozgonjuk et al., 2019). Consequently, those university students with higher smartphone use are more likely to develop pathologies such as depression or anxiety (Boumosleh \& Jaalouk, 2017; Konan et al., 2018; Kim \& Kwon, 2019; Kim et al., 2019) and poor academic performance (Chang et al., 2019).

For its part, age did not significantly influence smartphone addiction, despite what was found in other studies (Gligor \& Mozos, 2019).

In short, smartphone addiction is an endemic disease of 21st century society. Establishing measures for its prevention and treatment is a challenge for public administrations, especially in the field of education. This work has responded to the objectives of assessing the degree of smartphone addiction of university students in the degree in Primary Education at the University of Granada and determines the sociodemographic factors that influence addiction to the smartphone. At the same time, the research questions collected the findings of the study: (RQ1) The degree of addiction of future teachers is medium-high, as established by Polo, Mendo, León, and Castaño (2017). (RQ2) There are significant differences between age groups, work situations, and time invested (Gligor \& Mozos, 2019). Adults aged 26-29 are less likely to engage in these addictive behaviors. Conversely, the two extremes $18-21$ and 30 or older reflect higher levels of smartphone addiction. The work situation is also an incentive. Gender and 
Diaz-Aznar, Trujillo-Torres, Garcia, \& Jimenez. Sociodemographic factors influencing smartphone addiction in university students.

educational attainment are not determining factors. (RQ3) Time of use significantly influences smartphone addiction, so the more time spent on the mobile device, the higher the score (Rozgonjuk et al., 2019) on the SAS measurement scale.

Finally, among the limitations of the study is the establishment of the sample. When set with random criteria, they are representative of the population. However, it is a population limited only to future Primary Education teachers of a specific university. In future studies, it would be of interest to extend the sample to more degrees. Another limitation relates to independent variables, which were limited to a few sociodemographic factors. It is recommended that in future work, the factors that can influence smartphone addiction be expanded.

Finally, determining usage time as a predictor of smartphone addiction helps prevent this type of behavior. Based on this, education in the proper use of technology and the reduction of mobile device consumption should be fundamental pillars in the technological education that university students receive, being a key piece to avoid the negative consequences arising from abuse of the smartphone. 
Diaz-Aznar, Trujillo-Torres, Garcia, \& Jimenez. Sociodemographic factors influencing smartphone addiction in university students.

\section{References}

Alzubi, A. (2019). Teachers' Perceptions on Using Smartphones in English as a Foreign Language Context. Research in Social Sciences and Technology, 4(1), 92-104. Retrieved from https://ressat.org/index.php/ressat/article/view/399

Anshari, M., Alas, Y., \& Sulaiman, E. (2019, in press). Smartphone addictions and nomophobia among youth. Vulnerable Children and Youth Studies. doi:10.1080/17450128.2019.1614709

Aznar, I., Cáceres, M. P., \& Romero, J. M. (2018). Indicadores de calidad para evaluar buenas prácticas docentes de «mobilelearning» en Educación Superior. Education in the Knowledge Society (EKS), 19(3), 53-68. doi:10.14201/eks20181935368

Boumosleh, J. M., \& Jaalouk, D. (2017). Depression, anxiety, and smartphone addiction in university students- A cross sectional study. PLoSONE, 12(8), e0182239. doi:10.1371/journal.pone.0182239

Cha, S. S., \& Seo, B. K. (2018). Smartphone use and smartphone addiction in middle school students in Korea: Prevalence, social networking service, and game use. Health Psychology Open, 5(1), 1-15. doi:10.1177/2055102918755046

Chang, F. C., Chiu, C. H., Chen, P. H., Chiang, J. T., Miao, N. F., Chuang, H. Y., \& Liu, S. (2019). Children's use of mobile devices, smartphone addiction and parental mediation in Taiwan. Computers in Human Behavior, 93, 25-32. doi:10.1016/j.chb.2018.11.048

Elhai, J. D., Rozgonjuk, D.,Yildirim, C.,Alghraibeh, A. M.,\& Alafnan, A. A. (2019). Worry and anger are associated with latent classes of problematic smartphone use severity among college students. Journal of Affective Disorders, 246(1), 209-216. doi:10.1016/j.jad.2018.12.047

Gaspar, S., \& Cuesta, V. (2015). Adicción al smartphone. Análisis motivacional de uso entre nativos digitales. Opción, 31(4), 517-531.

Gligor, S., \& Mozos, I. (2019). Indicators of smartphone addiction and stress score in university students. Wiener KlinischeWochenschrift, 131, 120-125. doi:10.1007/s00508018-1373-5

Heo, Y. J., \& Lee, K. (2018). Smartphone addiction and school life adjustment among high school students: The mediating effect of self-control. Journal of Psychosocial Nursing and Mental Health Services, 56(11), 28-36. doi:10.3928/02793695-20180503-06

Herrero, J., Urueña, A., Torres, A., \& Hidalgo, A. (2019). Smartphone addiction: Psychosocial correlates, risky attitudes, and smartphone harm. Journal of Risk Research, 22(1), 81-92. doi:10.1080/13669877.2017.1351472

Hinojo, F. J., Aznar, I., \& Romero, J. M. (2018). Dispositivos móviles para el aprendizaje: Análisis de la investigación doctoral sobre mobilelearning en España. Texto Livre: Linguagem e Tecnologia, 11(3), 154-175. doi:10.17851/1983-3652.11.3.154-175

Jeong, Y. L., Suh, B., \& Gweon, G. (2019, in press). Is smartphone addiction different from Internet addiction? Comparison of addiction-risk factors among adolescents. Behaviour \& Information Technology. doi:10.1080/0144929X.2019.1604805 
Diaz-Aznar, Trujillo-Torres, Garcia, \& Jimenez. Sociodemographic factors influencing smartphone addiction in university students.

Kim, H. M., \& Kwon, H. Y. (2019). Relationships between depression, anxiety and smartphone addiction among college students. Asia Life Sciences, 18(2), 823-831.

Kim, S. G., Park, J., Kim, H. T., Pan, Z., Lee, Y., \& McIntyre, R. C. (2019). The relationship between smartphone addiction and symptoms of depression, anxiety, and attention-deficit/hyperactivity in South Korean adolescents. Annals of General Psychiatry, 18, 1. doi:10.1186/s12991-019-0224-8

Konan, N., Durmus, E., Türkoglu, D., \& Bakir, A. A. (2018). How is smartphone addiction related to interaction anxiety of prospective teachers? Education Sciences, 8, 186. doi:10.3390/educsci8040186

Kumcagiz, H. (2019). Quality of life as a predictor of smartphone addiction risk among adolescents. Technology, Knowledge and Learning, 24(1), 117-127. doi:10.1007/s10758017-9348-6

Kuss, D.J., Harkin, L., Kanjo, E., \& Billieux, J. (2019). Problematic smartphone use: Investigating contemporary experiences using a convergent design. International Journal of Environmental Research and Public Health, 15, 142. doi:10.3390/ijerph15010142

Kwon, M., Kim, D. J., Cho, H., \& Yang, S. (2013).The smartphone addiction scale: Development and validation of a short version for adolescents. PLOS ONE, 8(12), e83558. doi:10.1371/journal.pone.0083558

Lian, L. (2018). Alienation as mediator and moderator of the relationship between virtues and smartphone addiction among Chinese university students. International Journal of Mental Health and Addiction, 16(5), 1208-1218. doi:10.1007/s11469-017-9842-z

Noë, B., Turner, L. D., Linden, D. E. J., Allen, S. M., Winkens, B., \& Whitaker, R. M. (2019). Identifying indicators of smartphone addiction through user-app interaction. Computers in Human Behavior, 99, 56-65. doi:10.1016/j.chb.2019.04.023

Polo, M. I., Mendo, S., León, B., \& Castaño, E. F. (2017). Abuso del móvil en estudiantes universitarios y perfiles de victimización y agresión. Adicciones, 29(4), 245-255.

Qudah, M. F. A., Salamah, I., Attallah, S. F., Hashem, E. M. A., Alfnan, A. A., Aljomaa, S. S., \& Ateik, M. M. (2019, in press). Smartphone addiction and its relationship with cyberbullying among university students. International Journal of Mental Health and Addiction. doi:10.1007/s11469-018-0013-7

Rodríguez, R. (2017). Enganchados al móvil: España, 5o país del mundo que más tiempo pasa con el teléfono. El confidencial. Retrieved from https://bit.ly/2ihPOmg

Rozgonjuk, D., Elhai, J. D., Täht, K., Vassil, K., Levine, J. C., \& Asmundson, G. J. G. (2019). Nonsocial smartphone use mediates the relationship between intolerance of uncertainty and problematic smartphone use: Evidence from a repeated measures study. Computers in Human Behavior, 96, 56-62. doi:10.1016/j.chb.2019.02.013

Ruiz-Palmero, J., Sánchez-Rodríguez, J., \& Trujillo-Torres, J. M. (2016). Using Internet and dependence on mobile phones in adolescents. Revista Latinoamericana de Ciencias Sociales, Niñez y Juventud, 14(2), 1357-1369. doi:10.11600/1692715x.14232080715

Tarman, B., Baytak, A., \& Duman, H. (2015). Teachers' views on an ICT reform in education for social justice. Eurasia Journal of Mathematics, Science and Technology Education, 11(4), 865-874. 10.12973/eurasia.2015.1445a 
Tarman, B., Kilinc, E. \& Aydin, (2019). Barriers to the effective use of technology integration in social studies education, Contemporary Issues in Technology and Teacher Education, 19(4), Retrieved from https://www.citejournal.org/proofing/barriers-to-the-effectiveuse-of-technology-integration-in-social-studies-education/

Wang, H. Y., Sigerson, L., \& Cheng, C. (2019). Digital nativity and information technology addiction: Age cohort versus individual difference approaches. Computers in Human Behavior, 90, 1-9. doi:10.1016/j.chb.2018.08.031 